\title{
Medio ambiente, recursos naturales y paisaje agrario en los espacios medievales (siglos VIII-XV) Introducción
}

\author{
Miriam PARRA VILLAESCUSA
}

\section{Author:}

Miriam Parra Villaescusa

Departamento de Historia Medieval, Historia Moderna y Ciencias y Técnicas Historiográficas. Universidad de Alicante (Alicante, Spain)

miriam.parra@ua.es

https://orcid.org/0000-0003-0714-6216

Acknowledgment: Mi agradecimiento a todos los autores y las autoras que han participado en este número de la revista por su accesibilidad, disponibilidad, esfuerzo y trabajo para formar parte de esta publicación.

\section{Citation:}

Parra Villaescusa, M. (2021). Medio ambiente, recursos naturales y paisaje agrario en los espacios medievales (siglos VIII$\mathrm{XV})$. Introducción. Anales de la Universidad de Alicante. Historia Medieval, (22), 9-25.

https://doi.org/10.14198/medieval.20985

(c) 2021 Miriam Parra Villaescusa

Licence: This work is licensed under a Creative Commons Attribution 4.0 International License (CC BY 4.0).
La organización del paisaje, ya sea agrario, pecuario u otro, es resultado de una lógica social. Como sistema socio-ecológico, el paisaje no es una realidad estática, más bien todo lo contrario. Como construcción social es dinámico, estuvo y está en continua transformación, ya sea en clave de desarrollo o de retroceso. En los últimos años el estudio de la mutación del medio ambiente, del paisaje, los ya definidos paisajes históricos, o la explotación de los recursos naturales en el pasado, ha sido una cuestión de creciente interés analizada desde diferentes ópticas. Las preocupaciones de nuestro mundo actual por un cambio climático que plantea la búsqueda de conformar una simbiosis sostenible entre la vida humana y la natural, ha provocado que haya una mayor atención por el conocimiento de estos asuntos, por el uso de los recursos naturales, por las viabilidades de las relaciones ser humano-medio ambiente, por mirar hacia atrás lanzando preguntas sobre cómo fue su uso y gestión y cómo hemos ido avanzando hasta nuestra realidad paisajística y medioambiental actual. Incluso sobre cómo se consideraron e interiorizaron, desde un plano mental, socio-cultural o ideológico, las relaciones naturaleza y sociedad.

La observación histórica de los paisajes rurales engloba variados aspectos a través de los cuales podemos vislumbrar la realidad socioeconómica de las sociedades medievales. La sincronía entre los desarrollos ambientales y humanos impli- 
có la existencia de importantes sinergias entre ellos (Campbell, 2016, pp. 20-21; Mouthon, 2017). Durante la Edad Media en el Occidente europeo se fue produciendo un progresivo aumento de la presión antrópica sobre el medio y en especial sobre los espacios incultos. Fue un periodo de la Historia de gran mutabilidad ambiental y de cambios de escala en la gestión del espacio. Así, por ejemplo, la dinámica de ampliación de fronteras en la construcción política de las entidades de la Cristiandad latina medieval, significó un largo proceso de anexión de tierras entre los siglos centrales y finales del Medievo, como el acaecido en la Península Ibérica a costa de al- Andalus, que produjo modificaciones en los paisajes ocupados. En ellos se fue instaurando una antropización del entorno marcada por la potenciación de una agricultura extensiva basada en la ampliación de tierras cultivadas a costa de la reducción de la masa vegetal, los bosques o las marimas, para lograr maximizar la producción de cereales, la denominada "cerealización" o "agrarización" (Bartlett, 1993, pp. 152- 156; Torró, 2019, p. 28). Dinámica que "agrarizó" la economía rural y en la cual se experimentó un control cada vez más acérrimo de los espacios ganaderos. La agricultura y la ganadería comenzaron a organizarse a una magnitud superior, orientadas hacia especializaciones que permitieran sostener los requerimientos de las rentas señoriales, el aprovisionamiento de las ciudades y de los mercados. Comportamientos similares que se desarrollaron con sus singularidades en distintas partes europeas, y que suscita la necesidad de establecer comparativas entre distintos observatorios teniendo presente las condiciones ambientales que pudieron favorecer el desarrollo de opciones socio-económicas más ligadas al pasturaje o a las transformaciones agrarias, a ambas, o a otras relacionadas con la explotación de otros espacios del entorno natural.

Este proceso tuvo importantes consecuencias medioambientales y la creación de nuevos ecosistemas antropizados constituidos en relación a la complejidad de los sistemas socio-económicos de aquellos que los crearon, adaptaron y/o modificaron en base a sus intereses (Hoffmann, 2014, pp. 113-148). El incremento de tierras cultivadas, esquilmó áreas de alto valor productivo de ribera o boscosas, transformando el medio ecológico y originando una ruptura medioambiental en la explotación socio-económica de los recursos nutridos del bosque, el monte o el marjal. Roturaciones a gran escala, proyectos de irrigación y/o drenaje, nuevos recorridos ganaderos sobre las masas forestales, influido también por los operadores mercantiles, que coexistieron en diferentes grados y combinaciones, muestran que se produjeron señales de estrés ambiental (Hoffamann, 2014, pp. 156-158).

Las huellas de esta humanización progresiva del medio natural rompió los equilibrios socio-ecológicos de los paisajes que habían sido configurados por las sociedades o culturas preexistentes. De ahí que sea ineludible analizar la realidad material de estas realidades paisajísticas precedentes para calibrar las alteraciones y los impactos que pudo generar fenómenos como la privatización creciente de espacios 
comunales, la disminución de espacios incultos y la domesticación antrópica de los restantes espacios naturales. Metamorfosis que no fueron ajenas a disputas sociales y de poder por el uso de esos espacios, y a una necesidad de una mayor regulación y control de su aprovechamiento para conseguir una cierta "sostenibilidad" en la explotación económica del espacio rural. Búsqueda de un nueva sintonía socioecológica que no fue incompatible con los cambios, sino que se intentó conseguir a partir de ellos. Es por ello crucial centrar la mirada en el estudio de los paisajes medievales en las transformaciones, en los factores del cambio, del equilibrio o el desequilibrio. Así, la historiografía medieval ibérica ya ha desterrado la idea de continuidad en los asentamientos, la organización del espacio, del paisaje y de la gestión de los recursos naturales tras las conquistas cristianas peninsulares sobre los territorios bajo dominio de al-Andalus.

Desde el Medievalismo, los paisajes rurales han sido observados desde distintos planteamientos devenido del sentido poliédrico del término paisaje, que ha implicado progresivamente la necesidad de acometer su observación desde la multidisciplinareidad, cada vez más instaurada con éxito en la ciencia histórica. Son muchas las aportaciones que han abierto la vía hacia el análisis más detallado y perfilado de cuestiones asumidas conceptual y metodológicamente desde la Historia Rural, la Historia Agraria, la Historia Medioambiental, como desde la Arqueología medioambiental y del Paisaje (donde se engloban la Hidráulica y la Agraria). Este avance en la investigación y la combinación de diversas perspectivas historiográficas ha introducido un nuevo vocabulario y método en la indagación de los paisajes históricos medievales, insertándose en la reflexión teórica y analítica los conceptos de riesgos y vulnerabilidades de las sociedades y la naturaleza ante los cambios climáticos y la transformación de los entornos producto del intercambio vital entre ambas (Soens, 2018; Gerrard et al, 2013). Las transiciones en la naturaleza y en la sociedad generaron "regímenes socio-ecológicos" donde clima y sociedad, biología y ecología, microorganismos y humanos, comprendieron distintos componentes de la dinámica de dichos sistemas (Campbell, 2016, pp. 19-29). Por ello, la historia rural medieval, no puede abordarse sin una perspectiva ecológica, puesto que las sociedades cambiaron y adaptaron los diversos espacios que ocuparon para ajustarlos a sus necesidades en una interacción inherente entre las mismas y el medio ambiente.

En este sentido, se ha aumentado el conocimiento sobre los paisajes, el medio ambiente y el uso de los recursos naturales, en el territorio de la Europa medieval. En el caso peninsular, se ha priorizado en la observación de los paisajes agrarios irrigados, de los sistemas hidráulicos andalusíes y de los feudales. Por lo que refiere a estos últimos, principalmente se ha puesto el foco en los efectos generados tras las conquistas cristianas, hecho que implicó adaptaciones y cambios de los espacios cultivados bajo la órbita de las exigencias de los poderes cristiano-feudales, con la 
roturación de tierras sobre espacios incultos como humedales o montes ${ }^{1}$. Asimismo, temáticas que habían sido menos analizadas, como los espacios de secano o la ganadería están siendo cada vez más abordadas, aunque con menos aportaciones hasta la fecha para el periodo andalusí ${ }^{2}$. Asuntos de estudio en el ámbito ibérico pero también extrapolables al europeo en general, donde se busca integrar el examen de los registros documentales escritos y arqueológicos, con la introducción cada vez más presente de técnicas arqueológicas para acometer lecturas arqueomorfológicas del paisaje, análisis geoarqueológicos o paleobotánicos (García-Contreras et al, (2020); Pluskowski, et al, 2011) y zooarqueológicos (Villar y García, 2017; García y Moreno, 2018; García, García-Contreras y Pluskowski, 2021). Una combinación metodológica y de fuentes que aboga por la multidisciplinareidad para reconstruir los paisajes rurales medievales, incluyendo no sólo los agrarios o ganaderos, sino también las marismas o los medios acuáticos (Vanslembrouk, Alexander y Thoen, 2005; Arias, García-Contreras y Malpica, 2019; Haidvogl, Hoffmann, Didier, Jungwirth y Winiwarter, 2015). Así, las últimas aportaciones historiográficas muestran que la clave es continuar en esta línea de interdisciplinareidad; llave para el enriquecimiento metodológico desde los nuevos avances tecnológicos y teóricos ligados a ellos. Todo un progreso investigador que ha supuesto que se abandone la postulación de un mundo rural medieval que creó un paisaje inamovible. Las investigaciones mediante análisis combinados, han mostrado las grandes posibilidades de reconstrucción paleoambiental en cronologías de larga duración y la comprensión del entorno natural no como escenario pasivo, sino como un factor cambiante con sustratos movibles naturales y humanos que produjeron diversos resultados, variados paisajes o ecosistemas humanizados.

Del mismo modo, la línea actual que se busca desarrollar dentro de la historiografía medieval es tratar de asumir el estudio del mundo y el paisaje rural desde una perspectiva más amplia y global, aunque todavía quede por aportar y avanzar en este sentido. Los paisajes rurales medievales fueron mucho más que agrarios y ganaderos, sino que fue una realidad más extensa y sobre todo más diversa ${ }^{3}$. El espacio rural debe ser comprendido inserto en la interrelación entre lo culto y lo inculto, en la diversidad natural y paisajística de un todo orgánico. Se ha de tener presente en su

1 Entre otras muchas referencias a estudios en este sentido: Esquilache, 2018, 2019; Kirchner y Virgili, 2019; Glick, 2007; Malpica y García-Contreras, 2017; Martín Viso, 2016; Rao, 2015; Retamero y Torró, 2018; Torró y Guinot, 2012, 2018. Tengo presente el extenso listado de trabajos que no son recogidos; no es pretensión de esta "Introducción" realizar todo un vaciado historiográfico de todas las aportaciones en estas temáticas, sino reflejar un elenco general de destacadas publicaciones que son muestra de este avance en el conocimiento de los paisajes rurales medievales.

2 A este respecto, entre otras publicaciones, puede consultarse: Retamero, 2010; Villar Mañas, 2013; Pascua Echegaray, 2012.

3 Valga como muestra de apertura y amplitud de miras de larga trayectoria historiográfica, la reciente publicación: Müller, 2021. 
observación histórico la globalidad de los recursos naturales que comprendía el área rural y su importancia en las economías medievales: desde los campos cultivados a las redes pecuarias, desde el agua a los pastos, desde el bosque a los ríos, desde las marismas a las plantas vegetales. La explotación del medio natural y antropizado, devino en el desarrollo y potenciación de actividades como la agricultura, la ganadería, la apicultura, la caza, la pesca, la recolección, pero también en procesos de transformación de materias primas (con el uso de la molinería, la obtención de tintes o manufacturas), siendo estas el elemento primigenio de sectores como el alimentario, el textil o el constructivo. Por ello, el medio, el entorno, los recursos naturales fueron entes de un paisaje en mutación por su propio uso humano, como bienes de producción, de consumo, de intercambio, de mercado, fuentes de energía, entre otros.

En este contexto historiográfico y en esta línea presentada, se enmarca la propuesta y fruto de la temática elegida para presidir el dosier monográfico contenido en este número 22 de la revista "Anales de la Universidad de Alicante. Historia Medieval". Bajo el título "Medio ambiente, recursos naturales y paisaje agrario en los espacios medievales (siglos VIII-XV)" este apartado especial de la publicación pretende mostrar la amplitud de temas en la indagación histórica del medioambiente y de los paisajes en cronología medieval, partiendo de la idea de la necesidad de unir los tres términos, medio ambiente, recursos naturales y paisaje agrario, para su propia comprensión entendiéndolos como un todo interconectado. Con ello, la idea que preside y es nexo de unión de los artículos recogidos, busca mostrar la variabilidad de estos tres términos y su interrelación en su empleo y cambio, que derivó en la construcción de espacios rurales, agrarios, ganaderos u otros que englobamos en naturales. El propio enunciado que titula el monográfico muestra la perspectiva de larga duración y amplia espacialización de su contenido, para manifestar la diversidad de los tiempos y de los ecosistemas configurados. Los trabajos reunidos han sido realizados por grupos de investigación e investigadores del panorama nacional e internacional que centran sus líneas de estudio histórico, directa o indirectamente, en el paisaje y los recursos naturales desde un punto de vista amplio. Abordan distintas temáticas relacionadas con la cuestión que preside este número en diferentes áreas peninsulares y más allá del territorio ibérico: la transformación del paisaje rural como resultado de la roturación de tierras y la consecuente pérdida de los espacios incultos (marismas, pastos, bosque), así como sus efectos sobre el medio ambiente (flora y fauna); el uso de recursos naturales como fuente de energía; la relación recursos naturales, espacio agrario y ganadería, y la delimitación de pastos para el desarrollo de la actividad ganadera; la explotación de los recursos aportados por el bosque como materias primas; la explotación de humedales, en este caso, del humedal salino, salinas para la extracción de sal; y por último, el análisis del uso, obtención, producción y destino de otros recursos naturales que permitieron 
el desarrollo de actividades productivas que han ocupado un lugar secundario en la historiografía medieval como la apicultura o la pesca.

En el marco de la expansión agraria y colonizadora de la Europa cristiana latina occidental, es donde se inscriben los cuatro primeros artículos. De esta manera, Helena Kirchner y Antoni Virgili, producto de la investigación que han llevado a término en los últimos diez años en los espacios agrarios del bajo Ebro -a partir del estudio de documentación escrita (repartos, traspasos y transacciones de tierras) y datos procedentes de la práctica arqueológica-, abordan los resultados obtenidos del examen de los espacios agrarios de ribera vinculados a ciertos asentamientos rurales andalusíes y a la ciudad islámica de Madina Turtusa (actual Tortosa (Tarragona), poniendo el foco en las transformaciones producidas sobre los mismos tras la conquista cristiano-feudal en los siglos XII y XIII. Estos espacios de ribera aparecen denominados en la documentación escrita como "algeziras" o "insulae" y se constata por los autores su localización, delimitación y realidad material en las riberas del Ebro, en los meandros y en las desembocaduras de los torrentes, rodeados totalmente o parcialmente por el agua fluvial, y expuestos a continuos cambios por las inundaciones, la sedimentación y la erosión, pero estables para otorgarles un destino agrícola. Tal y como exponen los autores, una explotación agrícola permanente que "salvo excepciones" no se puso en práctica en época andalusí -aunque sí de los recursos naturales que podían aportar tales como pastos, caza, sal, sosa o recursos forestales de acceso libre-, pero que sí fue impulsada por los señores feudales en la dinámica de asentamiento de colonos, repartimiento de tierras y colonización catalana del espacio en el Doscientos. Tras la conquista, los señores feudales, a partir de los intereses de la oligarquía dirigente y bajo el impulso del cabildo de Tortosa o la encomienda del Temple, adaptaron el aprovechamiento del entorno en base a sus nuevos requerimientos con una nueva administración de los recursos y una sustitución parcial de su utilización a partir de "programas de colonización agraria de sectores hasta entonces incultos" como eran estas áreas de ribera, con la consecuente ampliación del área cultivada -principalmente con cereal y viña- que a menudo precisó de la construcción de canales de drenaje.

En relación con estos procesos de ampliación del espacio cultivado y sus consecuencias sobre el medio, Julián Clemente Ramos plantea los cambios y desequilibrios medioambientales producto del aumento demográfico y la expansión de una economía agraria extensiva -a partir del crecimiento del terrazgo cerealista- que se desarrolló en el territorio castellano, en concreto, en el área de la meseta y las zonas meridionales, entre las primeras décadas del siglo XV y finales del siglo XVI. Se trata de una reflexión de carácter general en la que los aspectos ambientales se contextualizan en el contexto demográfico y socioeconómico castellano y dentro de los procesos de cambio europeos, no necesariamente de la misma cronología. El autor focaliza su discurso en las consecuencias de la extensión de la agricultura 
sobre el medio ambiente, en especial sobre los espacios boscosos que vieron reducida su extensión y con ello la fauna salvaje alterado su ecosistema vital. Indicadores de transformaciones y desequilibrios medioambientales producto de una creciente presión humana ante el aumento demográfico, la agrarización de la economía rural y un mayor control del tránsito del ganado, al hilo de la expansión castellana en las tierras situadas al sur del Tajo. Desarrollo que facultó una "profunda transformación ambiental" en la que se pasó de un paisaje dominado por el bosque, la vegetación natural y los pastos a otro de predominio agrícola, sobre todo cerealícola, donde el territorio se ordenó en favor de la agricultura. Más aún, el bosque comenzó a percibirse como un recurso limitado y necesitado de protección. Hecho que tuvo como resultado buscar la potenciación de una nueva silvicultura para pretender estabilizar un "modelo de explotación sostenible" con un control más acérrimo de su uso y mediante la repoblación vegetal de montes emprendida por iniciativa privada (monasterios), real, y/o municipal, donde los oficiales intentaron promover una utilización más racional de los recursos forestales y de la actividad cinegética.

Por su parte, en estrecha relación con los procesos descritos por el profesor Julián Clemente, el texto de José Juan Cobos presenta las modificaciones en el paisaje durante el transcurso del siglo XV al siglo XVI en la comarca de Antequera (Málaga). La ampliación de tierras de cultivo significó una presión humana sobre la vegetación original y la fauna salvaje. Un proceso no exento de polémica entre las instituciones y las comunidades rurales que el autor expone a partir del análisis de documentación escrita de distintos fondos archivísticos. La conquista cristiana de este territorio nazarí fue el arranque de litigios por la delimitación del territorio y por el uso de los recursos naturales en relación a los intereses de los señores feudales, y de un proceso de apropiación de tierras en consonancia con los intentos de repoblar el territorio anexionado. Unas tierras que se destinaron preferentemente a la agricultura cerealícola mediante nuevas roturaciones sobre humedales y/o espacios de monte que habían tenido un uso silvicultor anterior (madera, corcho, caza), que experimentó un claro retroceso. De esta manera, José Juan Cobos enlaza con la idea señalada también por Julián Clemente, en torno a la ruptura del equilibrio en la explotación del medio, de la "sostenibilidad ecológica" con las conquistas territoriales de los cristianos en el ámbito ibérico, que conllevó la pérdida de vegetación propia del bosque mediterráneo. Del mismo modo, ejemplariza concesiones de tierras a favor de conservar el área arbórea y controlar en cierta manera la presión sobre la fauna objeto de caza. A pesar de ello, el avance de la agrarización, alteró la obligación de no ocupar los terrenos de uso comunal que pasaron a ser de utilidad agraria, mutó el paisaje y se convirtió en causa de múltiples pleitos entre vecinos, unido a una mayor definición del control sobre el entorno natural por el órgano municipal de Antequera y el real, no exento de disparidades entre ambos niveles de poder. 
Fuera del territorio peninsular, desde el ámbito italiano, Giuseppe Gardoni, esboza la metamorfosis que el paisaje rural del valle del Po (Italia) experimentó entre los siglos VIII-XIII desde un examen paisajístico retrospectivo. El autor ha indagado en el estudio de documentación escrita editada e inédita (donaciones, repartos, traspasos de tierras, ordenanzas, pleitos) relativa al territorio de Mantua y, en particular, la zona cercana al río Po, constatando grandes y pequeñas empresas agrícolas destinadas a ampliar las áreas cultivadas "ad usum panis reducte". Iniciativas emprendidas desde la Iglesia Mantua y el monasterio de San Benedetto Polirone, aunque también por la ciudadanía común entre los siglos XII y XIII, que significaron un retroceso de las zonas boscosas, con la consecuente deforestación, pérdida de prados, y la realización de zanjas de drenaje para la desecación de marismas, espacios de ribera o en islas formadas por el Po y sus afluentes, para destinarlas al cultivo preferente de cereal y viña. Cuestión que fue elemento de controversias por la destinación productiva, el control de los recursos de ribera (recolección, pesca, pastos), y los trabajos emprendidos para su drenaje entre las comunidades rurales y los poderes señoriales monásticos. Las riberas a orillas del río, constituyeron entornos destinados principalmente a la caza y la pesca durante los siglos VIII-X. Los monasterios se beneficiaron de la concesión de grandes extensiones de esas tierras donde podían pastar sus animales y capturar peces y caza, como pretexto para atraer a la gente. Si bien, entre los siglos X-XII, los litigios se refieren en su mayor parte a las pretensiones de convertir en suelos agrícolas franjas fronterizas de bosques, valles y arroyos que trajeron consigo un desequilibrio entre la explotación de los recursos forestales, pastos, tierras, pesca o caza. Por ejemplo, el autor constata documentalmente en las marismas de Bagnolo y Formigada, propiedad del monasterio de Sant Andrea, la iniciativa a principios del siglo XIII de emprender la recuperación forestal exigiendo la plantación y cría de sauces, pero reservando derechos de pesca y caza. No obstante, a comienzos del Doscientos las tierras cercanas al Po habían cambiado su apariencia fruto de un poderoso programa de roturaciones agrarias que necesariamente implicó trabajos de contención de las aguas aunque en ocasiones fueran empresas que se consiguieran solamente a corto plazo.

En relación con esta tendencia al incremento de tierras cultivadas, de la demografía y de la producción agrícola, se sitúa el aumento de la edificación de molinos que utilizaban el agua como fuente de energía para su funcionamiento. Cuestión que también suponía un elemento de actividad antrópica sobre el medio natural ante el uso de los recursos hidráulicos como fuerza motriz para la molienda, como por la propia edificación de estas construcciones que no era sino otra acción humana sobre el paisaje. En este sentido, el artículo de Emilio Martín Gutiérrez analiza la problemática de los molinos de mareas de la bahía de Cádiz a finales del periodo medieval, cuya principal función fue transformar el trigo en harina para hacer pan. Un patrimonio inmueble que todavía puede contemplarse en muchos lugares de la costa 
atlántica europea. El aumento de la población y, por ende, la necesidad de una mayor producción alimentaria, entrañó que en el siglo XV e inicios del XVI se potenciara su edificación a partir de la utilización de las mareas como fuente de energía. Si bien, su construcción también estuvo relacionada con el mantenimiento de las explotaciones salineras. Así, asumiendo la interacción sociedad-medio ambiente, el autor entronca la construcción de estas infraestructuras con una problemática global, "la gobernanza en torno al aprovechamiento de los recursos naturales", conectando el caso de estudio de los molinos mareales en la bahía de Cádiz con otros en la fachada atlántica europea. Realiza un minucioso estudio analítico, proponiendo la necesidad de abordar la funcionalidad y los mecanismos hidrológicos de estos ingenios, desde una perspectiva interdisciplinar y dentro de una nueva lectura del paisaje. Asimismo, recoge una cartografía que permite vislumbrar una panorámica sobre la presencia de estas infraestructuras en las costas atlánticas españolas, portuguesas, francesas, holandesas, inglesas y belgas. De todo ello, extrae que los molinos de marea estuvieron asociados a ecosistemas marismeños en relación a explotaciones salineras, la pesca y la producción de las cosechas, en cuyas inmediaciones se situaban ciudades portuarias con entidad comercial, formando parte de conjuntos portuarios, donde se intentó "dompter la mer". Más en concreto, destaca casos de estudio de estas edificaciones en los estuarios del Loira y del Gironda y principalmente del Golfo de Cádiz donde ante el dinamismo poblacional, productivo (agrícola, pesquero y salinero) y comercial del último cuarto del siglo XV, el municipio, la oligarquía ciudadana y comerciantes genoveses, mostraron un interés creciente por la construcción de estos molinos. Peticiones, solicitudes y concesiones de su construcción que no estuvieron al margen de conflictos por el uso de las mareas, dentro del juego de intereses de poder y económicos de sus principales propietarios, fundamentalmente miembros de las oligarquías urbanas, que muestra la alta estima de estos ecosistemas de riparia.

No podemos comprender este avance en progresivo de ocupación agraria, o de la propia actividad agrícola en la Edad Media, sin tener presente la simbiosis necesaria que hubo entre agricultura y ganadería. La actividad ganadera se enmarca en el aprovechamiento de los recursos naturales derivado del uso de pastos para el sustento alimenticio y vital del tránsito y el apacentamiento de las reses y en su interrelación con los espacios cultivados e incultos. Se ha hablado con más incidencia de los paisajes agrarios, o los paisajes rurales como paisajes agrarios, pero sin duda en conexión a ellos ocuparon una parte fundamental los paisajes ganaderos. En este sentido, el artículo de Ferran Esquilache emprende una primera aproximación al análisis de los paisajes ganaderos andalusíes en el área valenciana; en concreto en el territorio que dependió fiscal y jurisdiccionalmente de Madīnat Balansiya. La actividad ganadera en época andalusí ha sido menos tratada dentro del Medievalismo que los aspectos relativos a la agricultura islámica peninsular, fruto en parte a la falta de fuentes escritas existentes al respecto y a las mayores dificultades para constatar 
la materialidad de los espacios ganaderos en el paisaje. No obstante, como señala Esquilache, la combinación en esta observación de un vaciado analítico de documentos escritos de época cristiana unido a la lectura de las morfologías del paisaje, faculta proponer ciertas hipótesis para identificar zonas de pasto, su uso y gestión en el periodo islámico. Siguiendo estas premisas metodológicas, postula que existió un movimiento del ganado local por dentro de los términos de las alquerías islámicas existentes en el área de estudio, en el que las comunidades rurales buscarían combinar el uso ganadero de dos tipos de pastos, de marjal y de montaña; cuestión que permitiría complementar la dieta de los animales, evitar el agotamiento de los pastos y garantizar el movimiento del ganado a partir de pactos entre las mismas. A ello se uniría, la existencia de una trashumancia o quizá trasterminancia, entre las montañas del interior y los marjales de la costa valenciana, basada en acuerdos tribales. Asimismo, para el final del periodo andalusí, propone la identificación de una privatización de los espacios comunales con la formación de rahales pertenecientes a la aristocracia estatal para su explotación al margen de las alquerías. Este planteamiento señalaría una evolución y cambio en la gestión y posesión de los suelos ganaderos en las centurias de dominación islámica, al igual que ocurrió en los espacios y sistemas hidráulicos agrarios. La posibilidad de la existencia de una ganadería trashumante basada en acuerdos tribales pone sobre la mesa la necesidad de intentar identificar y datar sus fases, su origen y evolución en los siglos X y XI en adelante. Como resalta el autor, "los estudios de ganadería andalusí deben ser siempre diacrónicos, o al menos presentar esta perspectiva, pues su funcionamiento no pudo ser exactamente el mismo durante todo el período andalusí porque la evolución de la sociedad debió influir en ella". Añade el requisito de analizar las áreas de pasto en relación con las zonas de cultivo y en especial con los marjales que debieron ocupar un lugar destacable en la economía campesina como pastos sin requerir grandes transformaciones. Si bien, señala la posible acción antrópica en el marjal de Pego y en Alfàndec/Valdigna mediante la realización de canales de drenaje para regular y controlar el exceso de agua con el objetivo de mantener o aumentar la superficie disponible para pastos.

Siguiendo el contenido del dosier, Marta Sancho Planas trata la importancia de la explotación de los recursos forestales en época medieval; tema poco tratado como objeto principal de estudio en la investigación hispánica medieval. La autora realiza un balance y visión global de los usos y actividades productivas ligadas a la recolección y la semi-agricultura que aprovechaba los recursos forestales, y la disponibilidad de datos en las fuentes escritas, arqueológicas, iconográficas y etnográficas para su investigación sobre todo por lo que refiere a los territorios catalanes y los Pirineos. El objetivo que prima es la identificación de actividades productivas vinculadas a especies vegetales no cultivadas en la Edad Media y plantea la posibilidad de que algunas de ellas fueran cuidadas o potenciadas en el mismo lugar en el que se 
desarrollaban espontáneamente a modo de semi-agricultura. Asimismo, apunta una metodología capaz de superar el silencio de las fuentes documentales y la escasez de los datos arqueológicos para estudiar el aprovechamiento de la vegetación silvestre, que permita poder comprender el encaje de los usos y las gestiones de los recursos forestales dentro de las economías rurales medievales. En intrínseca vinculación con esta línea de conocimiento del uso del bosque, se encuentra el trabajo de Javier López Rider, que analiza la utilización de la agalla vegetal extraída de diferentes árboles, sobre todo robles y encinas, en el espacio peninsular durante los siglos bajomedievales. La agalla vegetal se extraía y solía triturarse para usarse en trozos pequeños o en forma de polvo para procedimientos técnicos, a veces disuelto en líquidos como agua, aceite de oliva o vino, dependiendo del producto que se pretendiera elaborar. Principalmente, se empleó para obtener el color negro en tintas de escritura ferrogálicas y como curtiente en pieles y mordiente en la industria textil, pero también tuvo un destino medicinal y cosmético. Su destacable uso y consumo se refleja en su presencia desde las primeras décadas del siglo XIII en la Corona de Aragón y en la Corona de Castilla en el tráfico mercantil, junto a otras materias primas, que se mantuvo en las siguientes dos centurias, y también por su comercialización por el Mediterráneo Oriental. Recurso natural como materia prima para la elaboración de distintos productos, cuyas referencias, tal y como recoge el autor, son contenidas sobre todo en recetarios donde se menciona las sustancias empleadas, cantidades y método de trabajo para su conversión en bien de consumo, de intercambio y base de una actividad productiva complementaria a la agroganadera.

La siguiente publicación, enlaza con la explotación del humedal, en concreto del salino y la extracción de la sal. Su autor, Guillermo García-Contreras Ruiz, examina la organización social del espacio y la distribución de los asentamientos andalusíes en relación a la explotación de ciertas salinas del norte y este de Guadalajara y el sur de Soria, desde el asentamiento de las comunidades islámicas (siglos VIII al IX) hasta la conquista y colonización feudal de este territorio (XI-XII). Una investigación que construye metodológicamente a partir del análisis de fuentes arqueológicas y escritas. Estas salinas por sus propios condicionantes medioambientales, han sido explotadas a partir de complejos hidráulicos en los que se extrae el agua salada mediante norias de los manantiales de salmuera o endorreicos -fruto de la carga de sales del acuífero subterráneo-, para acumularla en balsas donde por evaporación solar y del viento se forma el grano del mineral. Si bien, como alude el autor, aunque se ha constata el uso de una veintena de salinas en la Edad Media, no se ha podido evidenciar restos arqueológicos de estas instalaciones fechables para esta cronología. Su reutilización a lo largo de los siglos ha supuesto continuas reformas y alteraciones de los materiales o elementos constructivos empleados para su explotación en el periodo medieval. Por ello, García-Contreras se aproxima a aprehender el uso de estas explotaciones salineras en relación al resto de elementos que generaron su uti- 
lización. Estos son, el componente y organización social de las comunidades andalusíes que las utilizaron y los núcleos de poblamiento y otros espacios productivos, agrícolas o ganaderos, ubicados en sus inmediaciones, mediante una observación del territorio desde la Arqueología del Paisaje. Con todo, vincula el aprovechamiento de estas salinas con ciertos asentamientos andalusíes -alquerías y poblados en altura- ubicados en las medias laderas de los cerros y sierras alejadas de los fondos de valle de la zona estudiada, cuyas poblaciones combinarían la extracción de la sal con la práctica ganadera y agrícola. La organización del poblamiento y la falta de estructuras constructivas relacionadas con el Estado, entre otros indicadores, le llevan a proponer "un aprovechamiento directo" e independiente de las salinas "por las comunidades rurales de base campesina", no de tendencia autárquica ni en una "horizontalidad social" del campesinado, y desarrollado "siempre que mantuviese una relación fluida en el pago de impuestos al Estado".

Los últimos tres artículos abordan otras dos actividades del mundo rural: la apicultura y la pesca. Por lo que refiere a la primera, en la Edad Media las abejas tuvieron una economía significativa devenida de una importancia social y cultural de sus producciones. Así, la cera fue impulsada por la práctica religiosa cristiana entre muchos otros usos, mientras que la miel proporcionaba el único edulcorante accesible antes que las importaciones de azúcar a gran escala. De esta manera, la apicultura fue una parte notable de la economía rural con la participación de campesinos con sólo unas pocas colmenas para una producción a pequeña escala, hasta apicultores especializados que la insertaban en un comercio internacional. En este marco, Lluís Sales i Favà, Alexandra Sapoznik y Mark Whelan, presentan un análisis de una amplia variedad de documentos del norte y del sur de Europa, que ejemplifican la importancia de la apicultura en el período medieval tardío en diferentes contextos ecológicos, economías y organizaciones sociales, que supusieron diferentes formas de esta actividad, tanto en su destino, como en su producción y gestión, entre el norte y el sur europeo. Los autores analizan el proceso de extracción de la miel y la cera de las colmenas, su manejo por los apicultores y la necesidad para su obtención de la instalación de colmenas. Proceso productivo que comprendía un uso del entorno y de otros recursos naturales, y que no estuvo exento de disputas y acuerdos en su gobierno y posesión. Los derechos para instalar colmenas y extraer el producto del interior a menudo estaban estrictamente regulados, bajo diversas formas, donde se vislumbra el interés de los señores en las colmenas y en los derechos sobre las tierras donde se instalaban. Los autores reflejan que los trabajos apícolas, con la presencia de una variedad de actores, no era una actividad aislada, sino que competía con otras. Así, en sus palabras, la apicultura proporciona una "lens through which to consider human intervention in the natural environment, demonstrating the extent to which the medieval landscape was regulated, managed, mediated and anthropized". Un bien natural que, aunque 
originalmente proporcionado por el contexto ecológico, fue modificado y utilizado para satisfacer una demanda social específica, y cuya apropiación, extracción y transmutación tuvo también un impacto ecológico sostenido, como indican, por soluciones técnicas y legales.

Más delimitado en el ámbito ibérico y también en torno a la actividad apícola, el artículo de Joaquín Aparici Martí se enmarca en el desarrollo del sector apícola en las comarcas del Maestrat y Els Ports de Morella en las tierras interiores castellonenses pero también en áreas limítrofes con el antiguo reino de Aragón y del sur de Cataluña. En esta área, examina a través de distintos tipos documentales (cartas de población, inventarios, testamentos, mandas pías, transacciones), la inserción de los productos relacionados con la apicultura en los circuitos de exportación de lanas y en las redes locales de captación y distribución que conectaban con los tráficos comerciales internacionales de Berbería, Francia o Italia durante los siglos XIV y $\mathrm{XV}$. Además, atiende a las repercusiones que este sector tuvo en la vida cotidiana y en el devenir económico de las comunidades de la zona que dedicaban parte de su tiempo a las labores que conllevaba esta actividad productiva para, bien la obtención de miel como alimento, o su transformación en manufactura como cirios. En definitiva, Aparici da muestra de la existencia y el desarrollo de la utilidad productiva de las abejas en la zona septentrional del reino de Valencia, exponiendo desde la producción inicial de la miel hasta la comercialización del producto y los elementos que la rodearon. Muestra que se pusieron en práctica acuerdos de reciprocidad entre localidades vecinas como también permisos temporales para facilitar la ubicación de las colmenas en uno u otro término municipal con el fin de mejorar los trabajos de obtención y la calidad, así como convenios para la exención de pago de tasas que conllevaron la estipulación de ordenanzas que regulaban y controlaban la producción apícola y su redistribución.

Por último, Pablo José Alcover Cateura centra su artículo en la pesca. En concreto, el tema que guía su trabajo es la pesca del esturión en el reino de Valencia, Aragón y Cataluña durante los siglos XIV-XV, examinando su consumo como alimento. Como señala el autor, la ingesta de este pescado se convirtió en un indicador de rango social elevado, siendo utilizado para diferenciar las mesas de las clases altas de las no privilegiadas. Aportaba un elemento de distinción, como indicador de ostentación y poder social. El control de su pesca por parte de las monarquías y los poderes locales catalano-aragoneses, como en otros estados occidentales, es muestra que se intentó asegurar su abastecimiento controlando su precio y regulando su captura y pesca en distintos territorios de la Corona de Aragón. El autor proporciona datos obtenidos de la documentación escrita así como de estudios publicados de arqueofauna y realiza una panorámica comparativa de su pesca en los cursos fluviales de la Corona de Aragón con la acometida en los del reino de Inglaterra, Hungría, Croacia o Italia para resaltar elementos de similitud. Alcover entiende que el estudio 
de la pesca "no puede ser comprendida sólo desde la economía, sino que formaba parte de un todo relacionado".

Al apartado del dossier monográfico, se une el de Miscelánea, donde en este número de la revista se recogen dos aportaciones que aunque singularizadas, se interrelacionan con la temática del monográfico. En la primera de ellas, el profesor Simone Rosati plantea una reconstrucción de la explotación y gestión de los recursos naturales en los territorios pontificios en los siglos XIV y XV a partir de un estudio histórico- jurídico de los testimonios dejados por las corporaciones o gremios de agricultores de la zona geográfica consideradas de Tarquinia, Viterbo, Tuscania y Roma. Realiza una exploración de su estructura y funcionamiento, desde el punto de vista organizativo, jurídico y estatuario que nos faculta a aproximarnos al conocimiento del uso y gestión de los recursos naturales en los dominios temporales de la Iglesia. Por otra parte, José Antonio López Sabatel asume una investigación panorámica que pretende recopilar la información relativa al utillaje agrícola empleado por el campesinado gallego en las fuentes escritas medievales de la Alta y Plena Edad Media.

En definitiva, esta publicación recoge un conjunto de trabajos acometidas por un elenco de investigadores que ofrece una panorámica representativa de distintas líneas de análisis histórico del medio ambiente, de los recursos naturales y de los paisajes, con una variedad de casos notables tanto en lo que refiere al aspecto cronológico como el espacial. Unos artículos de investigación que resaltan la importancia de estas cuestiones para conocer las sociedades y el mundo rural medieval en toda su amplitud socio-cultural y medioambiental. Todos ellos, ponen de relieve la importancia de proseguir indagando en la mutación de los sistemas socio-ecológicos para caracterizar con más detalle los ecosistemas humanizados y las lógicas socioculturales que se dieron en la simbiosis entre utilización, adaptación y modificación de los paisajes rurales medievales. Manifiestan la necesidad de abordar el estudio de recursos naturales y actividades menos analizadas hasta la fecha que las puramente agrícolas, como la ganadería en interrelación con los espacios agrarios, la pesca, la apicultura, los recursos forestales o vegetales, $u$ otros tantos que aquí no son tratados. Además, se señala por todos los autores, de una u otra manera, el necesario ímpetu en seguir o poner en práctica, la interdisciplinariedad y la combinación de distintas técnicas, fuentes y especialistas para avanzar en la investigación de los temas tratados, más aún para las ocasiones en las que se atisba una carencia de disponibilidad de documentos escritos o restos arqueológicos. En esta línea, para concluir, cabe apuntar que en el caso ibérico, esta amplitud de miras en la comprensión de la explotación socio-económica del medio ambiente, debe proseguir y enfatizarse para la observación del mundo rural feudal tras las conquistas cristianas, pero del mismo modo debe ser para el andalusí -del que disponemos de menos aportaciones hasta la fecha-, intentando salvar mediante la innovación metodológica, los obstáculos 
devenidos de la posible falta de fuentes. Esta ausencia de conocimiento constatada, en ocasiones, sobre el aprovechamiento del paisaje, más allá del agrario, por los andalusíes, puede dificultar calibrar la irrupción de las conquistas cristianas sobre las actividades y espacios productivos andalusíes, lo cual puede conducirnos a equívocos en las valoraciones de los alcances, las transformaciones y/o las continuidades.

\section{REFERENCIAS BIBLIOGRÁFICAS}

Arias-García, J., García-Contreras Ruiz, G. y Malpica Cuello, A. (eds.) (2019). Los humedales de Andalucía como sistemas socio-ecológicos: aproximaciones multidisciplinares. Editorial Alhulia.

Bartlett, R. (1993). The Making of Europe. Conquest, Colonization and Cultural Change (950-1350). Princeton University Press: London.

Campbell, B. M. S. (2016). The great transition: climate, disease and society in the Late-Medieval World. Cambridge: Cambridge University Press.

https://doi.org/10.1017/CBO9781139031110

ESQUiLACHE MarTí, F. (2018). Els constructors de l'Horta de València. Origen, evolució i estructura social d'una gran horta andalusina entre els segles VIII y XIII. Valencia: PUV.

- (2019). Una herencia reconstruidda. Canvis físics i institucionals en les hortes fluvials andalusines després de la conquesta cristiana. En E. Vicedo (ed.), Recs històrics: pagesia, història i patrimoni. IX Congrés sobre sistemes agraris, organització social i poder local, (pp. 449-474). Edició d'Enric Vicedo.

Haidvogl, G., Hoffmann, R., Didier, P., Jungwirth, M., Winiwarter, V. (2015). Historical ecology of riverine fish in Europe. Acquat Sciences, (77), 315-324. https://doi.org/10.1007/s00027-015-0400-0

Hoffamann, R. C. (2014). An Environmental History of Medieval Europe. Cambridge: Cambridge University Press. https://doi.org/10.1017/CBO9781139050937

García-Contreras Ruiz, G. et al (2020). Lansdcapes of (re)conquest: dynamics of multicultural frontiers in medieval South-west Europe. Antiquity, 94, (375), el5, 1-8. https://doi.org/10.15184/aqy.2020.76;

GarCía, M. y Moreno, M. (2018). De huertas y rebaños: reflexiones históricas y ecológicas sobre el papel de la ganadería en al-Ándalus y aportaciones arqueozológicas para su estudio. Historia Agraria, (76), 7-48.

https://doi.org/10.26882/histagrar.076e01g

García, M., García-CONTRERAS, G. y Pluskowski, A. (2021). The zooarchaeological identification of a 'Morisco' community after the Christian conquest of Granada (Spain, early 16th century): sociocultural continuities and economic innovations. Archaeological and Anthropological Sciences. 17-57.

https://doi.org/10.1007/s12520-021-01288-2; 
Gerrard, C. M. and Petley, D. N. (2013). A risk society? Environmental hazards, risk and resilience in the later Middle Ages in Europe. Nat Hazards (69), 10511079. https://doi.org/10.1007/s1 1069-013-0750-7

GLICK, Th. F. (2007). Paisajes de conquista. Cambio cultural y geográfico en la España medieval. Valencia: PUV.

Guinot, E. y TORRÓ, J. (eds.) (2018). Trigo y ovejas. El impacto de las conquistas en los paisajes andalusíes (siglos XI-XVI). Valencia: PUV.

KirChNER, H. y Virgili, A. (2019). Espacios de cultivo vinculados a Madinat Turtusa (Tortosa, Cataluña): norias, drenajes y campesinos (siglos VIII-XII). Edad Media. Revista de Historia, (20), 83-112. https://doi.org/10.24197/em.20.2019.83-112

SOENS, T. (2018). Resilient societies, vulnerable people: coping with Nort Sea Floods before 1800. Past $\mathcal{E}$ Present, 241 (1), 143-177. https://doi.org/10.1093/pastj/gty018

Malpica Cuello, A. y García-Contreras, G. (2019). La gestió de l'aigua en les zones humides de l'actual Andalusia en época andalusina. Afers. Fulls de recerca i pensament, 93, 409-434.

Martín Viso, I. (2016). Asentamientos y paisajes rurales en el Occidente Medieval. Madrid: Síntesis.

Mouthon, F. (2017). Le sourire de Prométhée. Lhomme et la nature au Moyen Âge, Paris: La Découverte. https://doi.org/10.3917/dec.mouth.2017.01

Müller, M. (2021). The Routledge Handbook of Medieval Rural Life. Routledge Handbooks.

PASCUA ECHEGARAy, E. (2012). Señores del paisaje. Ganadería y recursos naturales en Aragón, siglos XIII-XVII. PUV: Valencia.

PLUSKOWSKI, A. et al (2011). The ecology of crusading: investigating the environmental impact of holy war and colonisation at the frontiers of medieval Europe. Medieval Archaeology (55), 192-225.

https://doi.org/10.1179/174581711X13103897378564

RAO, R. (2015). I paesaggi dell'Italia Medievale, Torino: Carocci editore.

Retamero, F. (2010). Pautes per a l'estudi dels espais de secà a al- Andalus. Els espais de secà, en J. Brufal (ed.) (2010). IV Curs d'Arqueologia Medieval (pp. 3149).

RetAmero, F. y TORró, J. (eds.) (2018). From al-Andalus to the Americas (13th-17th centuries). Destruction and Construction of Societies. Leiden.

TORRÓ, J. (2019). Paisajes de frontera: conquistas cristianas y transformaciones agrarias (siglos XII al XIV). Edad Media. Revista de Historia (20), 13-46. https://doi.org/10.24197/em.20.2019.13-46

TORRÓ, J. y GUINOT, E. (eds.) (2012). Hidráulica agraria y sociedad feudal. Prácticas, técnicas, espacios. Valencia: PUV.

Villar Mañas, S. (ed.) (2013). Sal, agricultura y ganadería: la formación de los paisajes rurales en la Edad Media. Granada. 
Villar mañas, S. y García, M. (eds.) (2017). Ganadería y arqueología medieval. Granada: Alhulia.

Vanslembrouk, N., Alexander L. y Thoen, E. (2005). Past landscapes and presentday techniques: reconstructing submerged medieval landscapes in the western part of Sealand Flanders. Landscape History, 27, 52-64.

https://doi.org/10.1080/01433768.2005.10594571 